\title{
Service Quality Improvement of Outpatient Blood Collection by Lean Management
}

\author{
Shui $\mathrm{Fu}^{\prime}$ \\ Xian-Guo $\mathrm{Wu}^{2}$ \\ Liang Zhang' \\ Li-Feng $\mathrm{Wu}^{\prime}$ \\ Zhang-Mei Luo' \\ Qi-Lei Hu' \\ 'Department of Clinical Laboratory, The \\ First People's Hospital of Yuhang District, \\ Hangzhou, Hangzhou, Zhejiang, 3III 00 , \\ People's Republic of China; ${ }^{2}$ Department \\ of Clinical Laboratory, The Second \\ Affiliated Hospital Zhejiang University \\ School Medicine, Hangzhou, Zhejiang, \\ 310009, People's Republic of China
}

Correspondence: Qi-Lei Hu Department of Clinical Laboratory, The First People's Hospital of Yuhang District, Hangzhou, No. 369 Yingbin Road of

Nanyuan Street, Linping District, Hangzhou, 31 I100, People's Republic of China

Tel +8657l 89369404

Email egglandmine@163.com
Objective: To explore the application effect of lean management in improving the quality of outpatient blood collection services.

Methods: For this study, a total of 146,907 patients whose blood was sampled by outpatient services between April 2020 and September 2020 were selected. We analyzed the influence of various factors on the waiting time and satisfaction levels of the patients for blood collection and eliminated confounders based on the results of the analysis. Lean management for the outpatient blood collection service was implemented in July 2020. Thus, the 38,275 cases sampled on weekday mornings between April and June 2020 were selected as the ordinary management group, while the 39,473 cases sampled on weekday mornings between July and September 2020 belonged to the lean management group. Finally, the changes in waiting time and the satisfaction levels of the patients were evaluated.

Results: The age and gender of the patients and the length of service of the staff, who administered blood collection had a negligible effect on the waiting time $(Z=-1.243$, $P=0.418 ; \mathrm{Z}=-1.569, P=0.389 ; \mathrm{Z}=-1.062, P=0.563$ ), while there was a statistical difference in the waiting time between different days and different sessions $(Z=-2.581, P=0.013$ and $Z=-4.672, P<0.001)$. We also found that the length of service of blood collection staff, day, session, and age and gender of patients did not have a meaningful effect on patient satisfaction $(\mathrm{P}>0.05)$. Overall, the median waiting time of outpatients decreased from $22 \mathrm{~min}$ to $13 \mathrm{~min}$ after the implementation of lean management $(Z=10.522, P<0.001)$, while the satisfaction level of outpatients increased from $95.37 \%$ to $98.33 \%\left(\chi^{2}=559.580\right.$, $\mathrm{P}<0.001)$.

Conclusion: The application of lean management can significantly shorten outpatient waiting time for blood collection, improve patients satisfaction levels, and enhance the overall patient experience. Thus, lean management can significantly improve the service quality of outpatient blood collection.

Keywords: lean management, outpatient blood collection, waiting time, satisfaction, service quality

\section{Introduction}

In recent years, with the continuous development of society and medical advancements, the concept of health has become more meaningful to people. Because of this, hospitals, as well as patients, are paying more attention to outpatient blood collection, which is one of the most common procedures during health examinations. $^{1,2}$ Considering that outpatient blood collection is an essential aspect of the medical service of hospitals, service quality offers an indication of the amenities a hospital provides, and good service is also essential for the establishment of the hospital brand. Therefore, service quality is a vital element for 
outpatient blood collection departments. ${ }^{3,4}$ The quality of the outpatient blood collection service can directly reflect the image of hospital management, and also affect the reputation of the hospital among the people. ${ }^{5,6}$ Moreover, it acts as a focus of activity for the "Three Goods and One Satisfaction" (good service, good quality, good medical morals, and satisfying the people), an initiative that was implemented by the national health system in China. ${ }^{7}$ For most health examinations in China, blood collection is performed in the morning, and outpatients are required to fast before their blood samples are taken. Thus, in most hospitals, due to large patient numbers and a relative shortage of medical resources, patient waiting time for blood collection is often lengthy and service quality can be compromised. $^{8-10}$ Prolonged waiting times not only make the patients feel uncomfortable and anxious but also harm the doctor-patient relationship and waste the patients' time, affecting their work and life. Therefore, reducing the waiting time of outpatients for blood collection and improving the experience of patients can effectively improve outpatient blood collection management quality, thus enhancing patient satisfaction and forming a good image for hospitals. However, devising methods for effectively reducing waiting times for blood collection has always perplexed outpatient blood collection service administrators, and waiting time is one of the foremost reasons for disputes and complaints from patients during diagnosis and treatment. Lean management is a management method that eliminates waste and maximizes value through simple but effective means in work. Lean management, as a delicate form of management, is simple, accurate, fine, and strict. It can eliminate practical difficulties in the system, process, and management methods, thereby making processes streamlined and efficient, significantly improving quality and optimizing service. ${ }^{11,12}$ Lean management can be utilized to reduce examination turnaround time, enhance patient satisfaction, improve medical quality, and increase patient safety. ${ }^{13,14}$ At present, the application of lean management in outpatient blood collection is still at an initial stage, and there is not yet a standard practice for it. For outpatient blood collection, lean management should be implemented across the entire process from spots to the entire area, and problems should be solved node by node by constantly remedying defects in the system. This achieves the goals of satisfying various patient-centered needs and improving the overall outpatient blood collection service quality. It also, realizes one of the core value of "Placing the feelings of patients and employees first" for our hospital. In this study, lean management was integrated into all aspects of outpatient blood collection, to shorten patient waiting times and improve the quality of the blood collection service. This in turn improved patient satisfaction while ensuring safe and satisfactory medical treatment for the patients.

\section{Materials and Methods Study Population}

The outpatient blood collection division started employing lean management in July 2020. The study included 146,907 patients who were provided the outpatient blood collection service in our hospital and completed a satisfaction survey between April and September 2020. This group included 69,897 males with a median age of 45 (1-89) years and 77,010 females with a median age of 46 (1-91) years. Among them, 68,575 cases underwent outpatient blood collection between April and June 2020, before lean management commenced. The other 78,332 cases occurred between July and September 2020, after the introduction of lean management. The selective biases caused by confounders (weekends, holidays, and afternoons) were eliminated based on a comparison of waiting times and outpatient satisfaction for blood collection, and according to different features, from April to September 2020 (Table 1). Consequently, the 38,275 cases sampled on weekday mornings between April and June in 2020, including 19,215 males with a median age of $45(1-90)$ years and 19,060 females with a median age of 46 (1-91) years, were placed in the ordinary management group. Then, the 39,473 cases sampled on weekday mornings between July and September in 2020, including 19,536 males with a median age of 46 (1-91) years and 19,937 females with a median age of 45 (1-90) years, were included in the lean management group.

\section{Methods}

The procedure for outpatient blood collection before the introduction of lean management was as follows: Patients are issued an inspection requisition form according to the doctor's instructions, then they take a numbered ticket from the queuing machine for outpatient blood sampling. Note that there is only one queue number, and no restrictions on the number of tickets examination subjects can take. Staff call the patients' names in due order for blood collection [no information in the laboratory information 
Table I Comparison of Outpatient Waiting Times and Patient Satisfaction for Blood Collection According to Different Variables

\begin{tabular}{|c|c|c|c|c|c|c|}
\hline \multicolumn{2}{|l|}{ Feature } & \multirow{3}{*}{$\begin{array}{c}\begin{array}{c}\text { Cases for } \\
\text { Investigation }\end{array} \\
72,153 \\
74,754\end{array}$} & \multirow{3}{*}{$\begin{array}{l}\text { Patient Waiting Time for Blood } \\
\text { Collection M (IQR) (min) } \\
19(27) \\
18(26)\end{array}$} & \multirow{3}{*}{$\begin{array}{c}\begin{array}{c}\text { Patient } \\
\text { Satisfaction } \\
\text { (Cases/\%) }\end{array} \\
69,909(96.89) \\
72,398(96.85) \\
\end{array}$} & \multirow{3}{*}{$\begin{array}{l}\mathbf{Z} \text { valuel } \\
\chi^{2} \text { value } \\
-1.062^{\#} \\
0.196^{*}\end{array}$} & \multirow{3}{*}{$\begin{array}{l}P \text { value } \\
0.563^{\#} \\
0.658^{*}\end{array}$} \\
\hline Length of service of & $\mathrm{I} \sim 3$ years & & & & & \\
\hline blood collection staff & $>3$ years & & & & & \\
\hline \multirow[t]{2}{*}{ Day of blood collection } & Working days & 109,759 & $21(28)$ & 106,295 & $-2.58 \mathrm{I}^{\#}$ & $0.013^{\#}$ \\
\hline & $\begin{array}{l}\text { Weekends or } \\
\text { holidays }\end{array}$ & 37,148 & $15(19)$ & $36,012(96.94)$ & $0.846 *$ & $0.358 *$ \\
\hline \multirow[t]{2}{*}{$\begin{array}{l}\text { Session of blood } \\
\text { collection }\end{array}$} & $\begin{array}{l}\text { Morning (8:00 } \\
\sim 11: 30)\end{array}$ & & & $101,056(96.84)$ & $-4.672^{\#}$ & $<0.00 \mathrm{I}^{\#}$ \\
\hline & $\begin{array}{l}\text { Afternoon } \\
(13: 30 \sim 17: 00)\end{array}$ & 42,562 & $3(5)$ & 41,250 (96.92) & $0.491 *$ & $0.484 *$ \\
\hline \multirow[t]{2}{*}{ Gender of patient } & Male & 69,897 & $17(26)$ & $67,670(96.8 I)$ & $-1.569^{\#}$ & $0.389^{\#}$ \\
\hline & Female & 77,010 & $19(28)$ & 77,010 (96.92) & $1.290 *$ & $0.256^{*}$ \\
\hline \multirow[t]{2}{*}{ Age of patient } & $\leq 12$ years old & 35,992 & $18(26)$ & $34,858(96.85)$ & $-1.243^{\#}$ & $0.418^{\#}$ \\
\hline & $>12$ years old & 110,915 & $19(27)$ & $107,449(96.88)$ & $0.05 I^{*}$ & $0.821^{*}$ \\
\hline
\end{tabular}

Notes: length of service of blood collection staff: 4 people: I-3 years, 4 people: $>3$ years; ${ }^{*}$ Mann-Whitney U-test; ${ }^{*}$ Chi-square test; patient satisfaction $=$ (number of very satisfied + mostly satisfied patients)/total number of patients surveyed $\times 100 \%$.

system(LIS)], scan/enter the patients' outpatient numbers to query the examination items, confirm the patients' identities, print the corresponding barcodes, then perform blood collection. Main problems: (1) At the blood collection windows, the management of supplies and supplies was disorderly, resulting in a time-consuming replenishment process for necessary provisions during the blood collection period. (2) The layout of the patient waiting area was unreasonable since there were some isolated areas where it was difficult to see the call screen. (3) There were deficiencies in the calling software, and the hardware was outdated. The calling system could identify both the outpatient number and the medical record number, but the LIS system could only read patient information corresponding to their outpatient number. Therefore, if a patient took a number using their medical record number, the outpatient number on the referral form would have to be scanned again manually for the patient's information and examination items to be read out, consequently wasting a significant amount of time. (4) The calling system was also outdated. It could not display the next patients in line, therefore patients could not prepare for blood collection in advance. Besides, relevant staff would have to wait until the patient found the correct window, thus wasting time for both blood collection staff and patients. Additionally, if the system encountered a patient whose name contained a rare Chinese character, a glitch in the system would prevent the screen from displaying the patient information. (5) The staff arrangement was unreasonable since queuing was based on a sequential basis and thus patients with special requirements for blood collection (such as infants) could not be allocated to windows with more experienced staff. This situation often led to unnecessary wasting of time, which prolonged the waiting time of patients. (6) Performance assessment was not adequate, which negatively affected staff enthusiasm. As a result, staff work efficiency was low and may have indirectly extended the waiting time for blood collection.

Relevant problems associated with this practice were identified and enhanced specifically. (1) Use "6S" to manage blood collection materials, ensuring the preparation of sufficient equipment in advance. Also, if necessary, arrange clerks of relevant divisions to replenish stock regularly. This reduces unnecessary walking, save time, and improve work efficiency.(2) Adjust the seating layout in the waiting area, so that patients can easily see the display screen, thus reducing the flow of people and avoiding congestion. (3) Update and maintain the hardware, and optimize the LIS system for patient information reading. Upgrade the handheld barcode reader to a more efficient seat barcode reader, so that staff members can quickly and accurately scan the outpatient number or medical record 
number with one hand. Perform regular maintenance on the queuing machine, computer, and display screen, to avoid hardware failures. Alter the LIS system, allowing it to acquire the test items automatically by reading patient information (outpatient number and medical record number). (4) Optimize the calling system by displaying the window number on the queuing ticket. As a result, patients do not waste time looking for the correct window or fail to find the corresponding window and miss their call, thus wasting the time of both doctors and patients. At the same time, display the next two patients in line on the call screen, giving patients have enough time to prepare. (5) Arrange blood collection windows and staff logically by arranging two separate windows for children and one preferential window (with calling rules improved simultaneously). Using more experienced staff for blood collection in the morning, thus promoting work efficiency and reducing patient waiting time. When there are fewer patients (such as in the afternoon), newer employees can be assigned to work. This can reduce the waiting time of patients for blood collection and also improve the practical skills of newer employees. (6) Reward outstanding staff based on their performance (number of patients receiving blood collection, number of vials filled, or the complexity of blood collection). Completing more work to a high standard rewarded with financial bonuses, thus raising the enthusiasm of the staff. This in turn shorten patient waiting time and improves patient satisfaction.

\section{Observation Indexes}

We compared the relevant indexes for evaluation before and after lean management. The patient waiting time for blood collection was calculated as the difference between the time when the patient obtained a number at the queuing machine and the time the label was printed on the LIS system. The patient satisfaction survey was based on the results of patient interviews, provided by the quality management department of the hospital. Satisfaction was evaluated as the number of "very satisfied" or "mostly satisfied" patients, expressed as a percentage of the total number of surveyed patients.

\section{Statistical Analysis}

SPSS 22.0 was used for data processing, and the Kolmogorov-Smirnov normality test was performed for analysis of the data distribution, with non-normal distribution data represented by the $\mathrm{M}$ (median) and IQR (inter quartile range). The rank-sum test was used for an intergroup comparison of non-normal distribution, and the chi- square test for a comparison of rates. If $\mathrm{P}<0$. 05, the result was considered to have statistical significance.

\section{Results}

\section{Factors Influencing the Service Quality of Outpatient Blood Collection}

According to the analysis on waiting times and patient satisfaction of 146,907 outpatients for blood collection, the length of service of blood collection staff, as well as patient age and gender did not have a substantial influence on the waiting time $(P>0.05)$, while the day and session had a significant effect on the waiting time $(P<0.05)$. The length of service of staff for blood collection, day, session, and patient age and gender had a negligible effect on patient satisfaction ( $\mathrm{P}>$ 0.05). Table 1 displays details of these results.

\section{Outpatient Waiting Times for Blood Collection Before and After Lean Management}

The Kolmogorov-Smirnov normality test was used to analyze the waiting time of outpatients for non-normal distribution, which could not be converted to a normal distribution, and was represented by $\mathrm{M}$ (IQR). For inter-group comparison, we adopted the Mann-Whitney $U$-test. After the launch of lean management, the waiting time of outpatients for blood collection was significantly shortened: the waiting time was less than $15 \mathrm{~min}$ for $54.26 \%$ of patients and within $30 \mathrm{~min}$ for $98.77 \%$ of patients. The overall waiting time in the lean management group was significantly shorter than for the ordinary management group (see Table 2 and Figure 1).

\section{Patient Satisfaction Before and After Implementation of Lean Management}

In the lean management group, $69.15 \%$ of patients were very satisfied and $29.17 \%$ were mostly satisfied, very satisfied was significantly higher than in the ordinary management group (57.98\%). However, mostly satisfied was significantly lower than in the ordinary management group (37.39\%). Moreover, only $0.89 \%$ expressed general satisfaction and $0.79 \%$ were dissatisfied, which was noticeably lower than in the ordinary management group $(2.40 \%$ and $2.23 \%$, respectively). Therefore, lean management significantly improved patient satisfaction ("very satisfied" and "mostly satisfied" patients were combined as satisfied patients). Table 3 provides detailed information about patient satisfaction. 
Table 2 Comparison of Waiting Times for Blood Collection Between the Two Groups

\begin{tabular}{|c|c|c|c|c|c|}
\hline Group & Cases & $\begin{array}{c}0 \sim 15 \text { min (Cases/ } \\
\%)\end{array}$ & $\begin{array}{c}16 \sim 30 \mathrm{~min} \\
\text { (Cases/\%) }\end{array}$ & $\begin{array}{c}>30 \text { min (Cases/ } \\
\%)\end{array}$ & $\begin{array}{l}\text { Overall Waiting Time (M [IQR }] \\
\text { min) }\end{array}$ \\
\hline $\begin{array}{l}\text { Ordinary management } \\
\text { group }\end{array}$ & 38,275 & $5,978 / 15.62$ & $20,599 / 53.82$ & $11,698 / 30.56$ & $22(3 I)$ \\
\hline Lean management group & 39,473 & $21,4 \mid 8 / 54.26$ & $|7,570 / 44.5|$ & $485 / 1.23$ & $13(16)$ \\
\hline$\chi^{2}$ value or $Z$ value & - & $\chi^{2}=33.054$ & $\chi^{2}=14.025$ & $\chi^{2}=41.586$ & $Z=10.522$ \\
\hline$P$ value & - & $<0.001$ & $<0.001$ & $<0.001$ & $<0.001$ \\
\hline
\end{tabular}

\section{Discussion}

In this study, we firstly analyzed the objective factors affecting the waiting time and satisfaction of outpatients for blood collection, with results showing that there was a statistical difference in the waiting time between different days and different sessions. In our hospital, blood collection for outpatients is relatively concentrated on weekday mornings, without any time for breaks. Therefore, we selected weekday mornings for the comparison of before and after the employment of lean management, to eliminate the influence of confounders, and meet the requirements for the accurate evaluation of lean management. In our study, the waiting time of outpatients for blood collection was of non-normal distribution, which was inconsistent with the previous reports of Boya ${ }^{6}$ and Feng-e. ${ }^{5}$ This may be caused by differences in outpatient blood collection processes and patient populations between hospitals. However, this study reinforced the outstanding clinical application value of lean management indirectly through the median waiting time of outpatients for blood collection. After lean management was introduced, slightly shorter waiting times than the reported average ${ }^{5,6}$ were recorded. Currently, there are few reports on the waiting time of outpatients for blood collection worldwide, therefore, it is difficult to compare our findings with relevant data from other countries. In this study, lean management led to improvements in the quality of the outpatient blood collection service, and patient-oriented service was enhanced by focusing specifically on the optimization of processes related to both patients and staff. During the course of our research, almost 1200 more outpatients were served under the lean management system than the previous system, while the number of staff remained unchanged. However, the median waiting time of outpatients

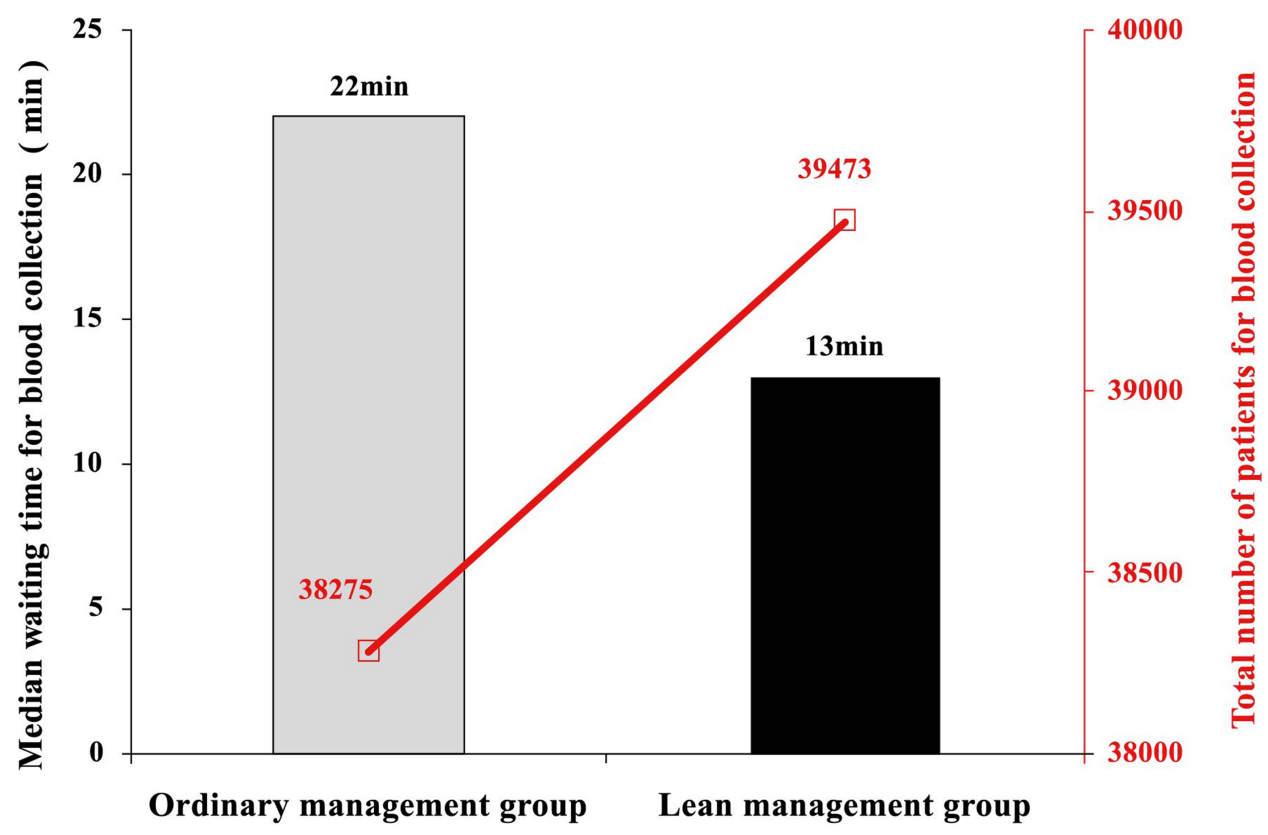

Figure I Comparison changes in the number of patients and waiting times for blood collection before and after the lean management. 
Table 3 Comparison of Patient Satisfaction Between the Two Groups

\begin{tabular}{|l|c|c|c|c|c|c|}
\hline Group & Cases & $\begin{array}{c}\text { Very Satisfied } \\
\text { (Cases/\%) }\end{array}$ & $\begin{array}{c}\text { Mostly Satisfied } \\
\text { (Cases/\%) }\end{array}$ & $\begin{array}{c}\text { General Satisfied } \\
\text { (Cases/\%) }\end{array}$ & $\begin{array}{c}\text { Dissatisfied } \\
\text { (Cases/\%) }\end{array}$ & $\begin{array}{c}\text { Satisfaction } \\
\text { (\%) }\end{array}$ \\
\hline $\begin{array}{l}\text { Ordinary } \\
\text { management group }\end{array}$ & 38,275 & $22,193 / 57.98$ & $14,311 / 37.39$ & $918 / 2.40$ & $853 / 2.23$ & 95.37 \\
\hline $\begin{array}{l}\text { Lean management } \\
\text { group }\end{array}$ & 39,473 & $27,296 / 69.15$ & $11,516 / 29.17$ & $350 / 0.89$ & $311 / 0.79$ & 98.33 \\
\hline$\chi^{2}$ value & - & 1048.061 & 591.239 & 275.879 & 272.537 & 559.580 \\
\hline$P$ value & - & $<0.001$ & $<0.001$ & $<0.001$ & $<0.001$ & $<0.001$ \\
\hline
\end{tabular}

for blood collection was reduced from $22 \mathrm{~min}$ to $13 \mathrm{~min}$. Although the results are encouraging, the requirements for the "Three Goods and One satisfaction" initiative are still not satisfied. $^{7}$ This may be related to the lack of an early warning mechanism in this study, based on the dynamic distribution of patient flow. The next step in our research is to define a flow warning algorithm, then establish a flow warning mechanism for the blood sampling window. This will coordinate supply and demand promptly, and by incorporating these measures into lean management, we can enhance the medical service for patients even further.

Lean management noticeably reduced the waiting time of outpatients for blood collection and increased patient satisfaction from $95.37 \%$ to $98.33 \%$. These results were more impressive than those reported by Zhongjun ${ }^{15}$ and Bo-Ya. ${ }^{6}$ In terms of satisfaction, lean management significantly increased the proportion of very satisfied patients, and lowered the number of dissatisfied patients, suggesting that outpatients for blood collection welcomed the "patient-centered" medical services based on lean management. The primary reason for this may be that lean management shortened the waiting times of patients, thus alleviating their impatient moods. It also improved the quality of the medical service, which would have also reduced the anxiety of the patients. Additionally, this study analyzed how lean management improved the efficiency of outpatient blood collection service by eliminating confounders, for which the choice of time was limited, ie, full coverage of time was not achieved. The next step in our research is to correct confounders by correction and to conduct a comprehensive analysis on how lean management improves the quality of the outpatient blood collection service and provides a more positive patient experience.

In summary, optimizing the outpatient blood collection process and environment for patients through lean management and by further integrating digital information technology into lean management generates many benefits. It not only shortens the waiting time of outpatients for blood collection but also increases patient satisfaction, thus earning a better reputation for the hospital and enhancing the overall development of the hospital. Lean management improves the sense of accomplishment of blood collection staff, reduces doctor-patient conflict, and improves the medical diagnosis and treatment experience of patients.

\section{Ethics Approval}

This study was carried out in accordance with the Helsinki Declaration. It was conducted with approval from the Ethics Committee of The First People's Hospital of Yuhang District, Hangzhou. Written informed consent was obtained from all participants.

\section{Disclosure}

All authors have contributed significantly to the manuscript and declare that the work is original and has not been submitted or published elsewhere. None of the authors have any financial disclosures or conflicts of interest.

\section{References}

1. Zhao S, He L, Feng C, He X. Improvements in medical quality and patient safety through implementation of a case bundle management strategy in a large outpatient blood collection center. Medicine (Baltimore). 2018;97(22):e10990.

2. Jain S, Chraiti MN, Pittet D, Mclaws ML. Blood collection guidelines for inpatients and outpatients, home-based care and long-term care facilities. $J$ Hosp Infect. 2020;104(4):600-602. doi:10.1016/j. jhin.2019.10.017

3. Kantartjis M, Melanson SEF, Petrides AK, et al. Increased patient satisfaction and a reduction in pre-analytical errors following implementation of an electronic specimen collection module in outpatient phlebotomy. Lab Med. 2017;48(3):282-289. doi:10.1093/labmed/ $\operatorname{lm} 024$ 
4. Giavarina D, Lippi G. Blood venous sample collection: recommendations overview and a checklist to improve quality. Clin Biochem. 2017;50(10-11):568-573. doi:10.1016/j.clinbiochem.2017.02.021

5. Feng-e W, Li-ling L, Jie L. Analysis on the effect of quality control circle for shortening the waiting time of outpatients for blood collection during peak hours. Int J Nulus. 2020;39(6):1055-1059.

6. Bo-ya Z, Yong G, Yuan-xin X, et al. Application effect of optimizing blood collection process design combined with PDCA method in shortening waiting time for blood collection of outpatients. Clin Res Pract. 2019;4(15):196-198.

7. Health Medical Zhengfa [2011] No. 30. Circular of the Ministry of Health concerning the implementation of "Three Goods and One Satisfaction" in the national medical and health system. Bulletin of the Ministry of Health of the People's Republic of China. 2011;04:26-31.

8. Task Force Members; ESC Committee for Practice Guidelines (CPG); ESC National Cardiac Societies. 2019 ESC/EAS guidelines for the management of dyslipidaemias: lipid modification to reduce cardiovascular risk. Atherosclerosis. 2019;290:140-205.

9. Sidhu D, Naugler C, Kantartjis M. Fasting time and lipid levels in a community-based population: a cross-sectional study. Arch Intern Med. 2012;172(22):1707-1710. doi:10.1001/archintern med.2012.3708

10. Yan X, Jun-hua T, Mei-li F. Influence of comfort care on the outpatients in the blood sampling room. J Qilu Nurs. 2020; 26 (19):110-112.
11. van Rossum L, Aij KH, Simons FE, van der Eng N, Ten Have WD. Lean healthcare from a change management perspective. $J$ Health Organ Manag. 2016;30(3):475-493. doi:10.1108/JHOM-06-20140090

12. Allaudeen N, Vashi A, Breckenridge JS, et al. Using lean management to reduce emergency department length of stay for medicine admissions. Qual Manag Health Care. 2017;26(2):91-96. doi:10.1097/QMH.0000000000000132

13. Verbano C, Crema M. Applying lean management to reduce radiology turnaround times for emergency department. Int J Health Plann Manag. 2019;34(4):e1711-e1722. doi:10.1002/hpm.2884

14. Kuo HC, Wei PC, Chang YC, et al. [The Utilization of Lean Management in Nursing Handover at a Psychiatric Acute Ward]. $\mathrm{Hu} \quad \mathrm{Li}$ Za Zhi. 2020;67(5):65-73. (Chinese). doi:10.6224/ JN.202010 67(5).09

15. Zhongjun M, Junhua T, Meili F. Application of continuous quality management in nursing quality management of infant patients in outpatient blood drawing room. J Qilu Nurs. 2021;27(5):21-24.
Patient Preference and Adherence

\section{Publish your work in this journal}

Patient Preference and Adherence is an international, peer-reviewed, open access journal that focusing on the growing importance of patient preference and adherence throughout the therapeutic continuum. Patient satisfaction, acceptability, quality of life, compliance, persistence and their role in developing new therapeutic modalities and compounds to optimize clinical outcomes for existing disease

\section{Dovepress}

states are major areas of interest for the journal. This journal has been accepted for indexing on PubMed Central. The manuscript management system is completely online and includes a very quick and fair peer-review system, which is all easy to use. Visit http:// www.dovepress.com/testimonials.php to read real quotes from published authors. 